\title{
Internet y socialización política. Consecuencias en la participación juvenil ${ }^{\star}$
}

\author{
Martín Echeverría* \\ José Antonio Meyer ${ }^{\star * *}$
}

Recibido: 2016-08-21 Enviado a pares: 2016-08-23

Aprobado por pares: 2016-09-06 Aceptado: 2016-11-11

DOI: 10.22395/angr.v15n30al

\begin{abstract}
Resumen
Una de las consecuencias políticas poco exploradas de Internet es la socialización política de los jóvenes, que nacieron y crecieron con la tecnología y son sus usuarios más asiduos. Para explorar esta interrogante desarrollamos un marco teórico que explique la potencialidad de la red para fungir como mecanismo de socialización, en un entendimiento tradicional como agente y en un entendimiento socioantropológico como escenario cultural juvenil. Utilizando las Encuestas Nacionales de Juventud aplicadas en México en 2010 y 2012, tomamos una cohorte de jóvenes de clase media en cuya trayectoria vital haya estado presente la tecnología, para analizar si la socialización de este grupo, mediada por la Internet, tiene un impacto en sus niveles de participación en comparación con otros medios de comunicación y agentes sociales. Encontramos que en efecto hay una relación entre el uso intensivo de la red y la participación política, pero esta es poco significativa. Concluimos que por lo menos en esa dimensión la presencia de Internet en la socialización de los jóvenes no tiene una consecuencia relevante, posiblemente por los niveles precarios de sofisticación política que se registran en dicho grupo.
\end{abstract}

Palabras clave: Internet, socialización, participación, jóvenes, política.

Este producto es resultado del proyecto de investigación "Jóvenes y política, ¿̇hacia una nueva cultura democrática? Creencias políticas autoritarias y democráticas en la juventud mexicana" financiado por el Instituto Nacional de Investigación y Formación en Políticas Publicas A. C. Fue realizado por el cuerpo académico "Comunicación política y ciudadanía en la transición democrática de México" del Instituto de Ciencias de Gobierno y Desarrollo Estratégico (ICGDE), BUAP. MÉXICO.

* Comunicólogo, doctor en Comunicación y Cultura (Universidad de Sevilla), máster en Comunicación Política y Opinión Pública (Universitat Pompeu Fabra, Barcelona). Miembro del Sistema Nacional de Investigadores, Nivel 1. Sus líneas de investigación son los formatos audiovisuales de la comunicación política, los estudios de periodismo político y la relación entre consumo mediático, jóvenes y política. Profesor investigador del Instituto de Ciencias de Gobierno y Desarrollo Estratégico (ICGDE) de la Benemérita Universidad Autónoma de Puebla, México echevemartin@yahoo. com.mx

... Doctor en Ciencias de la Información (Universidad de La Laguna, España), con especialidad en Comunicación Política y Opinión Pública. Integrante del Sistema Nacional de Investigadores, Nivel 1. Cuenta con más de 25 años de experiencia docente en instituciones del país y el extranjero. Ha sido responsable de más de 20 proyectos de investigación enfocados al estudio de la información pública, el tratamiento mediático y los procesos de opinión pública. Actualmente es el director del Instituto en Ciencias de Gobierno y Desarrollo Estratégico de la Benemérita Universidad Autónoma de Puebla, México. joseantonio.meyer@gmail.com 


\title{
Internet and political socialization. Consequences in youth participation
}

\begin{abstract}
One of the least explored consequences of the Internet is the political socialization of young people, who were born and raised with this technology and are their most prevalent users. To explore this issue we developed a theoretical frame that explains the potential of the Internet to act as a devise of political socialization, both as a traditional agency and as a place for young subcultures to rise. From the National Youth Survey conducted in Mexico in 2010 and 2012, we took a cohort of young, middle class sample, with access to this technology during their upbringing, and analyzed if their socialization process, intertwined with the Internet, has a consequence in terms of political participation, in comparison to other media and social agents. We found that there is indeed a relationship between the hard use of the Internet and political participation, but it is not significant. We conclude that at least in the dimension of participation, the presence of the Internet in young people's socialization is not relevant, perhaps because of poor levels of political sophistication among that group.
\end{abstract}

Key words: Internet, socialization, participation, young people, politics. 


\section{Introducción}

Lo que piensan los adultos acerca de los jóvenes entraña múltiples prejuicios. Respecto a su lugar en el sistema político, dos de ellos han cobrado fuerza a partir de la creciente visibilidad de aquel grupo social: el primero apunta a la pasividad, indiferencia y apatía juveniles hacia la política, según el cual hay una distancia insalvable entre esos grupos y el sistema político formal, e incluso respecto a una formación cívica "correcta". De manera más reciente, un segundo prejuicio alude indirectamente a este, pero en un sentido correctivo: que Internet, a través de su abundancia informativa y capacidad de relación puesta en funcionamiento por las redes sociales, está acercando a los jóvenes -sus usuarios natos- a la esfera de lo público, "redimiéndolos" de su indiferencia política previa. Gravita sobre el segundo prejuicio cierto halo de romanticismo juvenil, pero en el fondo ambas posturas son conservadoras: la juventud se asume como una etapa de transición a la adultez con poca capacidad de agencia, que necesita ser activada por la tecnología y sus ilimitadas posibilidades para tomar cuerpo como actor político.

Las posiciones de la academia no difieren de estas en ciertos aspectos: la concepción pasiva de la juventud, que hasta hace relativamente poco empezó a ser contestada por los estudios socio-antropológicos, así como las posiciones "tecnófilas" que surgieron al calor de la popularización de Internet, nutren un imaginario limitado respecto a las capacidades reales de ambos elementos, tanto del impulso movilizador de los jóvenes como de la capacidad de Internet para conformar una nueva ciudadanía.

La investigación académica del fenómeno, luego entonces, se hace necesaria por buenas razones: en primer lugar, el surgimiento reciente de movimientos juveniles alrededor del mundo y particularmente en México sugieren un revival de la juventud movilizada (largamente añorada de otras épocas) en particular a partir del uso intensivo de Internet y redes sociales, utilizado para organizar estos movimientos o simplemente manifestar descontento político, a modo de trinchera de denuncia, resistencia y oposición. En segundo lugar, la colonización de Internet en el tiempo libre de los jóvenes tiene, desde luego, implicaciones importantes al nivel instrumental, como las que mencionamos previamente, así como consecuencias potenciales en el nivel de socialización política, habida cuenta de que el medio ha llegado ya a su adolescencia y su masificación avanza a gran velocidad: del $45 \%$ de los mexicanos que son usuarios de Internet, los jóvenes de entre 18 y 34 años suponen el $40 \%$ de los ellos (y el $93 \%$ de ellos utiliza redes sociales)'. En tercer lugar, es destacable el hecho de que los jóvenes contemporáneos de México, a diferencia de otras generaciones, nacieron y crecieron en condiciones políticas democráticas que ofrecen a su participación un grado de pluralidad y libertad inéditas; ante estas condiciones es legítimo preguntarse hoy en qué medida los jóvenes utilizan Internet para fines políticos, cómo lo hacen y qué consecuencias ello produce en términos de participación política.

No obstante, es necesario advertir que las diferencias de acceso por nivel educativo son abismales. Según la ENVUD (2012), de los jóvenes de entre 18 y 29, los que tienen título universitario poseen Internet en un $65 \%$, pero los que tiene Preparatoria en un $39 \%$, Secundaria 38 \% y Primaria $5 \%$. Esto pudiera implicar que las diferencias en cuanto a prácticas y valores políticos asociados a la educación irían a la par con el acceso a Internet (Zabludovsky, 2012). 
La hipótesis de partida es que los sujetos que crecieron con Internet y lo utilizan con mayor asiduidad tendrán mejores disposiciones y prácticas de participación política² ${ }^{2}$ Para corroborar este aserto utilizamos la base de datos de la Encuesta Nacional de la Juventud en sus versiones 2010 y 2012, en un recorte de clase media, empleando las variables de uso de medios de comunicación y las de participación política e interés. A partir de sus cruces y correlaciones se intenta determinar si los usuarios asiduos de Internet presentan predisposiciones de participación política más acentuadas que los usuarios asiduos de otros medios de comunicación y cuáles son los aspectos que en efecto se acentúan -o bien atenúan- en los internautas.

Además de subsanar un aspecto un tanto descuidado en la academia, la constatación empírica que se presenta aspira a ajustar las imágenes que existen acerca de los jóvenes; por un lado, las que les asignan los atributos de apatía y pasividad políticas negligentes, y por otro, las que vaticinan una nueva generación de jóvenes activos y comprometidos, con poca consideración de los matices y la complejidad imbricada en dicho fenómeno.

\section{Internet, juventud y política. Flujos horizontales y verticales de socialización}

La posibilidad de que los internautas asiduos sean más participativos descansa en, por lo menos, dos supuestos: que Internet y sus herramientas les proporcionan un espacio idóneo de actividad a los jóvenes que ya son políticamente participativos, o bien, que el medio ha acompañado a los jóvenes con acceso a Internet en un tramo significativo de su trayectoria vital, de manera que ha permitido infundir en ellos los valores y actitudes que desembocan en dicho perfil. Ambas posibilidades consideran al medio como un instrumento relevante para la integración adecuada de los jóvenes al sistema político, por un lado como catalizador de predisposiciones previamente sedimentadas y, por otro, con capacidad socializadora.

El marco teórico y ejercicio empírico que se presenta explora esta segunda alternativa; desarrolla un argumento que permite comprender cómo estas tecnologías se imbrican en la socialización de las generaciones recientes que crecieron a la par del desarrollo de las mismas y espera, por tanto, que esto desemboque favorablemente en las predisposiciones de participación política; ello hace necesario definir a qué nos referimos por juventud, cuáles son los mecanismos de socialización que participan en su formación y cómo Internet contribuye a dicho proceso.

Para fines de este trabajo la juventud se entiende como un "proceso de adquisición [...] de los recursos necesarios para integrarse en la organización social y asumir nuevas dependencias, responsabilidades (personales y colectivas) [... y compromisos de tanto o mayor peso en su vida adulta" (Benedicto, 2008, p. 17). La juventud es un tiempo de espera

2 No se propone aquí una causalidad directa: al tiempo que Internet pudiera producir mayor participación; también es posible que los más participativos son los que mayormente usan Internet. En otras palabras, no necesariamente el medio ha formado mejor a los ciudadanos, sino que también pudiera ser que los ciudadanos mejor formados han encontrado en Internet un medio que les permite cristalizar sus disposiciones políticas. 
(moratoria) durante el cual los sujetos adquieren progresivamente las responsabilidades adultas de tipo productivo, conyugal, doméstico y parental, es decir, van preparándose para asumir un rol (Brito, 1998). La posición de los jóvenes en el campo político es, pues, deudora de esta lógica de sujeto-en-ciernes: si bien el derecho a participar mediante el voto se confiere de manera legal desde los 18 años (al menos en México), antes de ello los jóvenes son concebidos como individuos en formación de su identidad y rol cívicos, y en curso de descubrir y sostener públicamente sus propios intereses conforme estos se van autodefiniendo.

Ahora bien, de las diversas corrientes que explican la relación de los jóvenes con el campo de la política creemos pertinentes dos de ellas, contrapuestas en algunos aspectos: por un lado, la perspectiva de la socialización institucional, entendida con la metáfora de "vertical", y por otro, la comprensión de la juventud como una cultura más o menos autónoma, cuya socialización pudiera denominarse "horizontal", entre pares.

La primera corriente parte de una óptica generacional que remite al fenómeno de la reproducción de la cultura política mediante un mecanismo de socialización ${ }^{3}$. Este proceso implica la reunión de prácticas, informaciones y valores mediante agentes e instituciones políticas, que se encargan de introyectar actitudes, valores y creencias sobre el mundo político, con el fin de desarrollar orientaciones y conocimientos sobre las instituciones, sujetos y funcionamiento del sistema político, así como una personalidad e identidad políticas (Calderón, 2004). Como proceso de transmisión, el enfoque está puesto en la construcción de una posición de sujeto juvenil "en ciernes" desde las instituciones sociales (políticas, educativas, de salud, etcétera) que especifican lo juvenil en sus discursos y con ello definen problemáticas, políticas y acciones, si bien pudiera haber procesos de ruptura, renovación o reconstrucción, aunque más esporádicos (Benedicto, 2008; Fernández, 2003; Sandoval E Hatibovic, 2010).

Desde esta perspectiva son tres las instituciones clave de socialización: la familia, la escuela y los medios de comunicación. En la familia las posiciones políticas de los sujetos se producen no solo por el influjo directo de sus miembros mediante mecanismos de socialización primaria, sino también en virtud de la posición de esa familia en la estructura social que, a su vez, posibilita inserciones políticas específicas, por ejemplo, en el plano institucional (sindicatos, gremios de profesionistas o patrones) o ideológico (izquierda, derecha) (Megías, 2005, p. 21). La escuela, por su parte, es el espacio por excelencia de formación por parte del Estado, por lo que su influencia se ejerce desde los rituales cívicos, los libros de texto, el currículum de materias cívicas y éticas, así como los profesores como modelos de autoridad (Ibarra, 2003) .

3 A tal vertiente acompaña una explicación de "ciclo vital", según la cual "conforme los jóvenes van realizando su transición a la vida adulta e integrándose socialmente se definirán sus intereses específicos, lo cual les llevará a interesarse por los temas que se discuten en el espacio de la política. - puesto que las decisiones ahí tomadas ya empezarán a afectar sus intereses" (Benedicto, 2008, p. 14). En el presente trabajo obviamos tal explicación dado el objeto de indagación, pero es necesario tomarla en cuenta para una lectura más completa. 
Respecto a los medios de comunicación, los espacios periodísticos generan conocimiento y aprendizaje acerca del sistema político, pues el contacto constante de la ciudadanía con la política y las instituciones ocurre a través de procesos mediatizados (Dudley \& Gitelson, 2002). Desde la ficción -literaria, televisiva o cinematográfica- los medios puede transmitir modelos de conducta, valores y representaciones del entorno social, de sus problemáticas y de las características de los actores colectivos (Sánchez, 1996). En este grupo se colocaría Internet y las distintas aplicaciones que conlleva, cuya función sería más o menos correspondiente a las anteriores.

Por otra parte, la perspectiva socio-antropológica parte de la premisa de que los jóvenes conforman agregaciones culturales propias o "microsociedades" (Feixa, 1999) más o menos autónomas. En tales agregaciones se estaría dando un proceso de socialización predominantemente horizontal, entre pares, mediante el cual los sujetos se aculturizan y toman recursos de formación de sentido y expresión, pero, a la vez, producen sentidos y con ello una cultura relativamente independiente y autónoma a las generaciones que la precedieron (Macassi, 2001). En el terreno de la política ello implica a una escala amplia la conformación de una cultura y un campo político juvenil propios, más o menos autónomos respecto a las instituciones establecidas del Estado, mediante los cuales los jóvenes apropian, resignifican y disputan los discursos y funciones de estas (Estrada, 2008).

La "autonomización" de una cultura política juvenil tiene varias consecuencias y matices. Por un lado, desemboca en el surgimiento de una heterogeneidad de intereses que se decantan, a su vez, en una pluralidad de temas y niveles de compromiso: la ecología, la sexualidad, la paz, los derechos humanos, el rock, la expansión de la conciencia, etc., así como de expresiones singulares tales como la manifestación lúdica de las demandas o nuevas estrategias de socialidad política (IFE, 2003). Por otro lado, deriva en la fragmentación de diversas subculturas juveniles, singularizadas conforme a los escenarios sociales y políticos en que se conforman. La pertenencia por parte de sujetos o grupos juveniles a diversas subculturas políticas, constituidas como "comunidades afectivas" itinerantes (Maffesolli, 1988, en Zarzuri, 2010), da pie a la formación de "modos de vida política" altamente fragmentados, incluso contradictorios, que dificultad la pretensión del Estado de cohesionar y socializar bajo una sola narrativa y un solo discurso en miras a una identidad política unificada (Benedicto, 2008, p. 27). La inserción de los jóvenes en el campo político de las instituciones del Estado, luego, entonces, no es condición necesaria para una actividad y vida políticas, no está supeditada a una socialización e integración "funcional" en términos hegemónicos y puede ser vivida de maneras diversas.

La perspectiva "culturalista" deviene contrapuesta a la primera en algunos aspectos del proceso - dependencia versus autonomía al mundo adulto, uniformidad versus heterogeneidad en los resultados de la socialización, "dirigismo" del Estado versus formación entre pares-, no obstante que en los estudios empíricos son menos contrastantes y varios de sus supuestos se verifican: se constata, por un lado, un alejamiento y desafección juveniles hacia la política institucional (Fernández Poncela, 2009), pero, por otro, una reproducción efectiva de componentes actitudinales y valorativos cívicos, presentes de 
manera firme y predominante (IMJUVE, 2011). Se observa, asimismo, una predisposición a la participación en manifestaciones a favor de la paz, el medio ambiente, los derechos humanos o la cuestión indígena (IFE, 2003). Desde los estudios de los movimientos juveniles se observa que la horizontalidad en las relaciones políticas de estos grupos sustituye cada vez más a las jerarquías en la asignación de roles y tareas, al tiempo que se presenta un recelo hacia formas de centralismo político y de respeto a la heterogeneidad social (Aguilera, 2003; Balardini, 2005; Cardenas, Parra, Picón, Pinead, E Rojas, 2007).

Al observarlas de manera complementaria, ambas formas de socialización heredan generacionalmente un ethos político y, sobre todo, cívico hacia los jóvenes, no necesariamente vinculado con las prescripciones del Estado, que se compenetra, autonomiza y enriquece horizontalmente, de una manera singular en términos de los temas, valores y formas de participación juveniles. Lo que sigue es comprender cómo estos procesos intersectan con Internet, ya sea para prolongarlos o modificarlos en alguna medida.

\section{Internet como dispositivo de socialización política. Posibilidades teóricas de uso}

La relación entre el uso de Internet y un incremento en los niveles de participación política es un aspecto polarizado entre posiciones optimistas y realistas o "normalizadoras", aunque ambas reconocen las cualidades innovadoras de este medio: bajo costo, amplia capacidad para vehicular información política, diversidad de modos de expresión que admite, y disponibilidad de mecanismos de interpelación de los ciudadanos a las élites políticas en una direccionalidad no jerárquica de la comunicación (Echeverría, 2010; Tedesco, 2004).

Para las posiciones optimistas esto se traduce en el hecho de que Internet incrementa la participación política de los usuarios al proveer estructuras de oportunidad que incrementan el repertorio, en términos de alcance y profundidad, del comportamiento del ciudadano, mediante las cuales le es dada la oportunidad de actuar (Ward, 2005). La red combina los recursos off line-actividades políticas tradicionales-y on line para ampliar las oportunidades del ciudadano de concretar sus expresiones y preferencias políticas de manera más abierta, en sus propios códigos y con relativa inmediatez.

Las posiciones realistas o normalizadoras, por el contrario, ponen el énfasis en el escenario político cultural precario en donde se suscita la adopción de las TIC. Mazzoleni (2001) advierte que Internet no puede tener repercusiones de fondo en una cultura política que a escala general se caracteriza por un nivel deficitario de conocimiento, atención e involucramiento ciudadano en los asuntos públicos. La evidencia empírica presentada por estos detractores demuestra que el efecto político relevante de Internet es aplicable a aquellos que ya buscan información -con características socioeconómicas muy puntuales- de manera que el medio sirve en mayor medida para reforzar las posiciones previas y no cambiarlas (Tedesco, 2004).

Puesto que los horizontes "tecnófilos" o realistas previamente descritos respecto a Internet están descontextualizados, es necesario poner de relieve, cuando menos, 
tres de las condiciones actuales que modulan su uso y apropiación. En primer lugar, las tecnologías de comunicación e información llenan cada vez más los espacios de tiempo libre de los jóvenes y son de manera creciente lugares clave de socialidad y apropiación de referentes simbólico-culturales y políticos de dichos actores; en segundo lugar, y a raíz del proceso de democratización de México, los jóvenes gozan de espacios de participación y libertad de expresión mucho menos riesgosos que en épocas pasadas; un tercer aspecto apunta a una mayor disponibilidad de tiempo libre de manera cotidiana o en hiatos de desempleo o subempleo, debido a que los empleos son cada vez más escasos, precarios, flexibles e interrumpidos (Estrada, 2008; Macassi, 2001). Es la confluencia de estas circunstancias, y no solo la disponibilidad de la tecnología, lo que anticipa condiciones de socialización y participación políticas novedosas, aunque asentadas sobre fuerzas precedentes.

Dicho esto, el marco contextual y teórico previo permite dos entendimientos de Internet respecto a su papel en la constitución de un sujeto político: bajo una perspectiva de socialización vertical, los emisores institucionales instrumentalizan el medio para hacer llegar sus mensajes, que contienen elementos de información y conocimiento vertebrados en las instancias mediáticas del Estado (gobierno, partidos políticos), las periodísticas y, en cierta medida, las de la industria cultural (en lo ateniente a su capacidad para socializar políticamente). El sujeto juvenil es considerado como un proyecto de construcción ciudadana y fundamentalmente un consumidor de contenidos -crítico, a lo sumo-, de modo que la concepción de Internet se acerca a aquella que entiende medios como instrumentos de difusión.

De manera complementaria una teorización culturalista entendería a los jóvenes desde la perspectiva de productores autónomos de significados, que conforman subculturas en ocasiones distanciadas e incluso contestatarias de la cultura política hegemónica; Internet sería pues el territorio cultural amplificado en donde suceden el intercambio y la socialización entre pares. En virtud de dicha autonomía en Internet se suspenden momentáneamente las relaciones de subordinación a las que se encuentran sometidos los jóvenes, se multiplican los temas y referentes, y se suscitan nuevas lógicas de relación política, tales como la flexibilidad en los roles, la apertura a la heterogeneidad social y la ausencia de jerarquías. En ese nivel más general en Internet se constituyen comunidades subculturales que utilizan materiales de la cultura popular y la vida cotidiana para la construcción de identidades y corrientes de opinión alrededor de múltiples objetos vinculados con ellos, y cuyos elementos pueden ser la información y el conocimiento razonado -como lo prevén las teorías liberales-, pero que también admiten aspectos de emoción, sensación y experiencia (Hermes, 2006).

Así, como agencia de socialización política Internet superaría la actuación de los dispositivos mediáticos tradicionales que en ese sentido son de una eficacia muy relativa, por la poca atención que los contenidos informativos concitan en los jóvenes, decantados en mayor medida por el entretenimiento o bien por géneros informativos con altos componentes de este (Díaz Nosty, 2007; Lastra, 2006), por el descrédito que sostienen a 
la escasa información a la que están expuestos y por el entendimiento limitado de esta, consecuencia cognitiva de sus hábitos de consumo primordialmente audiovisual. (Portillo, 2003, 2004). En consecuencia, es dable pensar que Internet, en función de su horizontalidad y capacidad de generación de contenidos, rompe con estas tendencias produciendo una socialización política funcional que se traduzca, a final de cuentas, en una participación significativa en la esfera pública.

No obstante, la investigación empírica que relaciona la participación juvenil con el uso de Internet y redes sociales es aún ambigua. Por un lado, se constata una correlación positiva, aunque con ciertas limitaciones: que las actividades políticas online que requieren más tiempo se practican de manera menos frecuente que las que requieren poco tiempo y que dicha actividad está mayormente localizada en la modalidad de contacto, menos dependiente de la educación, habilidades y conocimientos de los usuarios que las otras modalidades de participación, donación y petición (Anduiza, Gallego, $\varepsilon$ Cantijoch, 2010; Vitak et al., 2010). Por su parte, las redes sociales ayudan a la adquisición de información -ya que es una manera fácil de acceder a ella- y, en consecuencia, al incremento de la discusión y reflexión, al tiempo que incrementan el capital social lo cual impacta en la multiplicación de oportunidades para la participación cívica y política (Gil de Zúniga, Nakwon, \& Valenzuela, 2012); en última instancia, la relación entre uso de Internet y participación política es, por lo menos, más fuerte que la relación encontrada entre esto último y el consumo de medios tradicionales (Bakker $\varepsilon$ de Vreese, 2011). En ese sentido en México se ha encontrado que el uso de Internet favorece las probabilidades de votar e incluso la mayoría de los internautas declaran haber votado en las elecciones de 2009 y 2012; de igual manera se ha constatado que la transmisión de mensajes a través de Internet impacta en la participación cívica y política (Guerrero, Rodríguez-Oreggia, \& Machuca, 2014; Muñiz \& Corduneanu, 2014).

Por otro lado, las posiciones contrarias subrayan que la participación depende más bien de la educación y experiencias pasadas, antes que de las tecnologías (Valenzuela, Park, \& Kee, 2009); o bien, que las personas solo buscan los contenidos que les interesan, y si el individuo no está interesado en política no utiliza el espacio on line para participar en estas actividades (Baumgartner \& Morris, 2010). La siguiente sección empírica intenta ofrecer evidencia sobre alguna de estas posibilidades, comprendiéndolas como indicadores de una socialización política en donde Internet ha tenido una participación relevante, por lo menos más significativa que otros medios de comunicación.

\section{Método}

El presente ejercicio exploratorio utiliza como insumo la Encuesta Nacional de Valores en Juventud de 2012, patrocinada por el Instituto Mexicano de la Juventud. De esta se tomó una muestra representativa de jóvenes de entre 18 y 29 años de edad, cohorte en el cual una buena parte nació o creció con Internet, han efectuado con mucha probabilidad su primer voto y no suelen presentarse variaciones internas en sus niveles de participación (Corduneanu, 2012); acudimos, por otra parte, a un indicador de clase media (la escolaridad 
mínima de algún progenitor, de nivel superior) ${ }^{4}$ para recortar la población a una franja de ingresos medios. También se tomaron datos de la misma encuesta en su edición 2010, en el mismo recorte demográfico, para explorar una variable ausente en la primera encuesta. Es así como de esta se extrajeron 570 casos, y de la segunda 337.

La decisión de circunscribir este estudio a una franja de clase media (de manera aproximativa) se originó por la necesidad de controlar las importantes variaciones en cuanto a disponibilidad de tecnologías de la información que se registran en la población de México, en particular respecto a la exclusión de los sectores populares de los dispositivos y usos de las TIC.

Por otro lado, dentro de estas encuestas identificamos variables que expresaran predisposiciones y patrones de participación política pasada y actual, puestas en relación con otras variables relativas al uso preferente y disponibilidad tanto de Internet como de redes sociales, estas presentadas en ocasiones de manera contrastada con otros medios de comunicación (como en el reactivo, "medio que más utilizas para informarte").

Se presentan, pues, tablas de contingencia que expresan esas relaciones, así como una correlación estadística categorial para las variables que la admiten.

\section{Hallazgos}

Agrupamos los hallazgos a lo largo de cuatro secciones, que serán descritas a continuación.

En primer lugar, extractamos información acerca de los diversos usos que los jóvenes le dan a Internet, de modo que podamos detectar aquellos vinculados con lo público y lo político; de tal suerte que tanto en la encuesta de 2010 como la de 2012 encontramos que dichos usos tienen escasa vinculación con lo político institucional.

En la encuesta de 2010 la mayoría de los usos de Internet (88 \%) conllevan un propósito de vinculación social, principalmente a través del chat (30\%), uso de redes sociales (30 \%) o correo electrónico (18 \%); un segundo uso, considerablemente menor, es el de acceder a contenidos de entretenimiento (36 \%) dentro de los cuales bajar o escuchar música es el principal (20\%), seguido de jugar videojuegos (8\%). Los usos que pensamos vinculan al usuario con información pública, entre los que están escuchar o leer noticias (3\%) o leer periódicos, libros o revistas (1\%), son mucho menores en su conjunto (5\%). Además, tal cifra no especifica el tipo de información, ante lo cual nos encontramos con la posibilidad de que la relacionada con lo político sea tan solo una fracción. Otras partes de la encuesta revelan que las redes sociales específicamente tienen usos públicos en una frecuencia estimable de casos, tal como organizar grupos de interés ( $25 \%$ ), o bien

4 Estamos conscientes de que esta sola referencia no indica satisfactoriamente la pertenencia de los jóvenes a la clase media; lamentablemente en dichas encuestas no hay indicadores de ingreso o propiedad que ayudaran a circunscribir mejor dicha categoría social. En función de ello cabe señalar que los resultados tendrán que ser leídos con esa cautela. 
protestar junto con otros (19\%). La encuesta no especifica si el grupo de interés se forma alrededor de objetos políticos, o si las protestas tienen ese matiz u otro tal como protestar contra corporaciones

Asimismo, en la encuesta de 2012 más de la tercera parte de los entrevistados utiliza Internet principalmente para estudiar (34.6\%), trabajar (23.77 \%) o chatear (19.9\%). Ver noticias o participar en blogs, lo cual implica algún grado de vinculación con lo público son actividades más bien marginales (2.1 \% y 1 \% respectivamente); con todo, la conexión a redes sociales, por las cuales pudiera recibirse y emitirse contenido político es un tanto mayor (11.11\%).

Los aspectos de interés por la política y participación en ella son otra dimensión desplegada en nuestro análisis (tablas 1 A y 1B). Los hallazgos revelan que hay una diferencia mínima en cuanto a la importancia que le atribuyen a la política entre las personas que utilizan Internet (2.6) y Facebook (2.5) para informarse, aunque el interés es ligeramente menor para los que se informan por Twitter (2.8), similar a los que consumen televisión (2.8). Ahora bien, quienes se informan por Internet demuestran un nivel ligeramente superior de interés (2) que quienes tienen Facebook (2.2) o Twitter (2.3), mismos que manifiestan el menor nivel de interés incluso que los consumidores de televisión (2.2) o prensa (2.0).

Asimismo, la diferencia en cuanto a la relevancia que la política tiene en sus vidas para quienes tienen o no tienen cuenta en redes sociales es nula (2.7 en ambos casos), así como su interés por la política (de 0.3 en favor de los que no tienen cuentas).

A pesar de estos tenues vínculos la frecuencia de conexión a Internet no parece vincularse con la relevancia de la política o el interés por ella. Las personas que se conectan todos los días le confieren una relevancia e interés moderados a la política (2.7 y 2.1, respectivamente), aunque estos indicadores no difieren mucho de los que se conectan menos de tres veces al mes ( 2.8 y 2.3, respectivamente) o con menor frecuencia (2.6 y 2.1, respectivamente). Variaciones similares manifiestan quienes declaran que actualmente participan en otros grupos: 2.8 quienes se conectan todos los días; 2.7 quienes se conectan al menos tres veces al mes, y 3 quienes se conectan con menos frecuencia.

Por el lado de la participación en alguna organización, los datos revelan que quienes se conectan con mayor frecuencia a Internet participan de manera más activa que quienes lo hacen a veces y quienes no; no obstante, las diferencias son mínimas, de +/ 0.3, y al parecer la posesión de una cuenta de redes sociales no se relaciona con la participación, que es idéntica entre quienes la poseen y quienes no (2.9). De la misma manera las diferencias entre el nivel de participación de quienes se informan por Internet, redes sociales y otros medios son también mínimas, de modo que los usuarios de TV, Internet y Facebook tienen una participación casi nula (2.9 en una escala en donde 3 es "nunca participo") mientras que los usuarios de prensa, en contraste, están un tanto más involucrados (2.7). 
Tabla 1A. Interés en la política y participación, en relación al consumo de medios

\begin{tabular}{|c|c|c|c|c|c|c|c|c|c|c|c|c|c|c|c|c|}
\hline & \multicolumn{12}{|c|}{ ¿Cuál es el medio de comunicación que más utilizas para informarte de lo que pasa en el país? } & \multicolumn{4}{|c|}{$\begin{array}{c}\text { ¿Tienes alguna cuenta en redes } \\
\text { sociales, ejemplo: Twitter, } \\
\text { Facebook, etc.? }\end{array}$} \\
\hline & \multicolumn{2}{|c|}{ Televisión } & \multicolumn{2}{|c|}{ Radio } & \multicolumn{2}{|c|}{ Periódico } & \multicolumn{2}{|c|}{ Internet } & \multicolumn{2}{|c|}{ Facebook } & \multicolumn{2}{|c|}{ Twitter } & \multicolumn{2}{|c|}{ Sí } & \multicolumn{2}{|c|}{ No } \\
\hline & $\mathrm{N}$ & $\%$ & $\mathrm{~N}$ & $\%$ & $\mathrm{~N}$ & $\%$ & $\mathrm{~N}$ & $\%$ & $\mathrm{~N}$ & $\%$ & $\mathrm{~N}$ & $\%$ & N & $\%$ & $\mathrm{~N}$ & $\%$ \\
\hline \multicolumn{17}{|c|}{ Actualmente, ¿Participas en alguna organización, asociación, grupo o movimiento? } \\
\hline Sí & 12 & $5.0 \%$ & 0 & $0.0 \%$ & 1 & $1.9 \%$ & 6 & $4.2 \%$ & 1 & $2.4 \%$ & 0 & $0.0 \%$ & 19 & $4.0 \%$ & 3 & $3.5 \%$ \\
\hline A veces & 5 & $2.1 \%$ & 1 & $3.4 \%$ & 1 & $1.9 \%$ & 3 & $2.1 \%$ & 3 & $7.1 \%$ & 1 & $25.0 \%$ & 10 & $2.1 \%$ & 5 & $5.9 \%$ \\
\hline No & 225 & $93.0 \%$ & 28 & $96.6 \%$ & 50 & $96.2 \%$ & 134 & $93.7 \%$ & 38 & $90.5 \%$ & 3 & $75.0 \%$ & 448 & $93.9 \%$ & 77 & $90.6 \%$ \\
\hline \multicolumn{17}{|c|}{ Tipo de grupo en el que participas } \\
\hline $\begin{array}{l}\text { Político (partidos, } \\
\text { movimientos) }\end{array}$ & 6 & $50.0 \%$ & 0 & $0.0 \%$ & 0 & $0.0 \%$ & 4 & $66.7 \%$ & 0 & $0.0 \%$ & 0 & $0.0 \%$ & 9 & $47.4 \%$ & 1 & $33.3 \%$ \\
\hline \multirow[t]{2}{*}{ No político } & 6 & $50.0 \%$ & 0 & $0.0 \%$ & 1 & $100.0 \%$ & 2 & $33.3 \%$ & 1 & $100.0 \%$ & 0 & $0.0 \%$ & 10 & $52.6 \%$ & 2 & $66 . \%$ \\
\hline & $\mu$ & $\begin{array}{l}\text { Desv. } \\
\text { est. }\end{array}$ & $\mu$ & $\begin{array}{l}\text { Desv. } \\
\text { est. }\end{array}$ & $\mu$ & $\begin{array}{l}\text { Desv. } \\
\text { est. }\end{array}$ & $\mu$ & $\begin{array}{l}\text { Desv. } \\
\text { est. }\end{array}$ & $\mu$ & $\begin{array}{l}\text { Desv. } \\
\text { est. }\end{array}$ & $\mu$ & $\begin{array}{l}\text { Desv. } \\
\text { est. }\end{array}$ & $\mu$ & $\begin{array}{l}\text { Desv. } \\
\text { est. }\end{array}$ & $\mu$ & $\begin{array}{l}\text { Desv. } \\
\text { est. }\end{array}$ \\
\hline $\begin{array}{l}\text { Actualmente, ¿Parti- } \\
\text { cipas en alguna orga- } \\
\text { nización, asociación, } \\
\text { grupo o movimiento? }\end{array}$ & $\mathrm{N}=2.9$ & $\mathrm{~N}=.5$ & $\mathrm{~N}=3.0$ & $\mathrm{~N}=.2$ & $\mathrm{~N}=2.7$ & $\mathrm{~N}=.8$ & $\mathrm{~N}=2.9$ & $\mathrm{~N}=.5$ & $\mathrm{~N}=2.9$ & $\mathrm{~N}=.4$ & $\mathrm{~N}=2.8$ & $\mathrm{~N}=.5$ & $\mathrm{~N}=2.9$ & $\mathrm{~N}=.5$ & $\mathrm{~N}=2.9$ & $\mathrm{~N}=.4$ \\
\hline $\begin{array}{l}\text { ¿Podrías decirme } \\
\text { por favor, qué tan } \\
\text { importantes son en } \\
\text { tu vida...? La política }\end{array}$ & $\mathrm{N}=2.8$ & $\mathrm{~N}=1.0$ & $\mathrm{~N}=3.0$ & $\mathrm{~N}=.9$ & $\mathrm{~N}=2.4$ & $\mathrm{~N}=1.7$ & $\mathrm{~N}=2.6$ & $\mathrm{~N}=1.1$ & $\mathrm{~N}=2.5$ & $\mathrm{~N}=1.0$ & $\mathrm{~N}=2.8$ & $\mathrm{~N}=.5$ & $\mathrm{~N}=2.7$ & $\mathrm{~N}=1.2$ & $\mathrm{~N}=2.7$ & $\mathrm{~N}=1.0$ \\
\hline $\begin{array}{l}\text { ¿Qué tanto te intere- } \\
\text { sas en la política? }\end{array}$ & $\mathrm{N}=2.2$ & $\mathrm{~N}=.9$ & $\mathrm{~N}=2.0$ & $\mathrm{~N}=.7$ & $\mathrm{~N}=2.1$ & $\mathrm{~N}=1.1$ & $\mathrm{~N}=2.0$ & $\mathrm{~N}=.7$ & $\mathrm{~N}=2.2$ & $\mathrm{~N}=.8$ & $\mathrm{~N}=2.3$ & $\mathrm{~N}=.5$ & $\mathrm{~N}=2.1$ & $\mathrm{~N}=.8$ & $\mathrm{~N}=2.4$ & $\mathrm{~N}=1.2$ \\
\hline
\end{tabular}

Fuente: elaboración propia con base en la Encuesta Nacional de Juventud en Valores 2012, Instituto Mexicano de la Juventud.

Tabla 1B. Interés en la política y participación, en relación a la frecuencia de consumo de medios

\begin{tabular}{|c|c|c|c|c|c|c|c|c|c|c|}
\hline & \multicolumn{10}{|c|}{ ¿Con qué frecuencia te conectas a Internet? } \\
\hline & \multicolumn{2}{|c|}{ Todos los días } & \multicolumn{2}{|c|}{$\begin{array}{c}\text { Varias veces a la } \\
\text { semana }\end{array}$} & \multicolumn{2}{|c|}{ Una vez a la semana } & \multicolumn{2}{|c|}{$\begin{array}{c}\text { De una a tres veces } \\
\text { al mes }\end{array}$} & \multicolumn{2}{|c|}{ Con menor frecuencia } \\
\hline & $\mathrm{N}$ & $\%$ & $\mathrm{~N}$ & $\%$ & $\mathrm{~N}$ & $\%$ & $\mathrm{~N}$ & $\%$ & $\mathrm{~N}$ & $\%$ \\
\hline \multicolumn{11}{|c|}{ Actualmente, ¿Participas en alguna organización, asociación, grupo o movimiento? } \\
\hline $\mathrm{Si}$ & 14 & $4.9 \%$ & 3 & $1.9 \%$ & 1 & $2.4 \%$ & 2 & $11.1 \%$ & 0 & $0.0 \%$ \\
\hline A veces & 8 & $2.8 \%$ & 2 & $1.3 \%$ & 0 & $0.0 \%$ & 1 & $5.6 \%$ & 0 & $0.0 \%$ \\
\hline No & 261 & $92.2 \%$ & 155 & $96.9 \%$ & 41 & $97.6 \%$ & 15 & $83.3 \%$ & 11 & $100.0 \%$ \\
\hline \multicolumn{11}{|c|}{ Tipo de grupo en el que participas } \\
\hline Político (partidos, movimientos) & 6 & $42.9 \%$ & 2 & $66.7 \%$ & 1 & $100.0 \%$ & 1 & $50.0 \%$ & 0 & $0.0 \%$ \\
\hline \multirow[t]{2}{*}{ No político } & 8 & $57.1 \%$ & 1 & $33.3 \%$ & 0 & $0.0 \%$ & 1 & $50.0 \%$ & 0 & $0.0 \%$ \\
\hline & $\mu$ & Desv.est. & $\mu$ & Desv.est. & $\mu$ & Desv.est. & $\mu$ & Desv.est. & $\mu$ & Desv.est. \\
\hline $\begin{array}{l}\text { Actualmente, ¿Participas en alguna } \\
\text { organización, asociación, grupo o } \\
\text { movimiento? }\end{array}$ & $\mathrm{N}=2.8$ & $\mathrm{~N}=.5$ & $\mathrm{~N}=2.9$ & $\mathrm{~N}=.5$ & $\mathrm{~N}=3.0$ & $\mathrm{~N}=3$ & $\mathrm{~N}=2.7$ & $\mathrm{~N}=.7$ & $\mathrm{~N}=3.0$ & $\mathrm{~N}=.0$ \\
\hline $\begin{array}{l}\text { ¿Podrías decirme por favor, qué tan } \\
\text { importantes son en tu vida...? La } \\
\text { política }\end{array}$ & $\mathrm{N}=2.7$ & $\mathrm{~N}=1.1$ & $\mathrm{~N}=2.8$ & $\mathrm{~N}=1.2$ & $\mathrm{~N}=2.3$ & $\mathrm{~N}=1.0$ & $\mathrm{~N}=2.8$ & $\mathrm{~N}=1.1$ & $\mathrm{~N}=2.6$ & $\mathrm{~N}=1.1$ \\
\hline ¿Qué tanto te interesas en la política? & $\mathrm{N}=2.1$ & $\mathrm{~N}=.9$ & $\mathrm{~N}=2.2$ & $\mathrm{~N}=.7$ & $\mathrm{~N}=2.1$ & $\mathrm{~N}=.8$ & $\mathrm{~N}=2.3$ & $\mathrm{~N}=.7$ & $\mathrm{~N}=2.1$ & $\mathrm{~N}=.5$ \\
\hline
\end{tabular}

Fuente: elaboración propia con base en la Encuesta Nacional de Juventud en Valores 2012, Instituto Mexicano de la Juventud. 
Estos indicadores se traducen y visibilizan fácilmente en términos de porcentajes: tan sólo el 4 \% de los usuarios duros de Internet participa en alguna organización, aunque el $5 \%$ de los consumidores de televisión, el $1.9 \%$ de los de prensa y el $2.4 \%$ de los de Facebook lo hacen, de modo que las diferencias son mínimas entre consumidores de TV e Internet y probablemente debidas al azar. Un fenómeno similar se observa en la frecuencia de conexión al medio. Si bien las personas que sí participan y se conectan todos los días son más numerosas (14) que las que lo hacen varias veces (3) o una vez a la semana (1), en términos relativos -comparando la intensidad de uso entre sí- no resultan más participativos los grupos más conectados, que los menos.

En estos indicadores también incluimos la división en grupos que participan en agrupaciones políticas y no políticas; desafortunadamente las frecuencias son tan bajas que es difícil realizar una comparación medianamente indicativa.

Otro cruce de variables se relaciona con las motivaciones que condicen a la participación política; estas son, en nuestros datos, de una naturaleza intrínseca o extrínseca y, dentro de ella, condicionada por alguna circunstancia o incentivo, por coerción de la autoridad o sencillamente tal motivación no se concreta (tabla 2). Los consumidores "duros" de ciertos medios se vinculan en mayor o menor medida a estos niveles de motivación; aquí los usuarios de Internet y Facebook tienen una ventaja moderada en cuanto a motivación intrínseca y tipos de motivación circunstancial frente a usuarios de otros medios.

Respecto a la primera (expresada por el reactivo "siempre se debe participar en política") esta se manifiesta en cierta medida superior en usuarios de Facebook (12 \%) e Internet (10 \%) en comparación con usuarios de radio (7 \%) y TV (5\%). También hay una diferencia notable en las personas que se manifiestan no motivadas a participar en absoluto: el $5 \%$ de usuarios de Facebook y $2 \%$ de Internet lo afirman, en tanto 4 \% de los usuarios de TV y 7 \% de usuarios de radio mantienen esa posición; así, los usuarios de Internet son los menos desmotivados a participar en política, aunque no por mucho.

En cuanto a la motivación extrínseca, otras categorías de respuesta dan la pauta de una ventaja moderada de parte de los usuarios de Internet. Cuando esta se relaciona con la "posesión de información y responsabilidad" es superior en usuarios de Internet (37 \%) y Facebook (37 \%) que los de TV (25\%) e incluso prensa (34 \%). Cuando media la indignación ("cuando hay que protestar por una injusticia") también es superior en usuarios de Internet (14\%), no así en las de redes sociales (9.8\%), que es inferior a los usuarios de TV (13\%) y similar a los de periódico (9\%). En un sentido negativo, la motivación a participar cuando se obtiene algún beneficio es inferior para usuarios de Internet (13\%) que para los de TV (17\%), pero superior en los usuarios de prensa (9\%), radio (7 \%) y Facebook (7 \%).

Asimismo, en cuanto a la motivación por coerción ("participar cuando es obligatorio") los usuarios de Internet y Facebook son los que menos la suscriben (24 \% y 29 \%, respectivamente) en comparación con los de periódicos (43\%), radio (39 \%) y TV (36 \%), en porcentajes sensibles. 
Tabla 2. Condicionantes de participación política en relación al consumo de medios

\begin{tabular}{|c|c|c|c|c|c|c|c|c|c|c|c|c|c|c|c|c|c|}
\hline \multirow{3}{*}{$\begin{array}{l}\text { ¿En qué ocasiones } \\
\text { consideras que se } \\
\text { debe participar en } \\
\text { política? }\end{array}$} & \multicolumn{12}{|c|}{$\begin{array}{l}\text { ¿Cuál es el medio de comunicación que más utilizas para informarte de lo que pasa } \\
\text { en el país? }\end{array}$} & \multicolumn{4}{|c|}{$\begin{array}{l}\text { ¿Tienes alguna cuenta en } \\
\text { redes sociales, ejemplo: } \\
\text { Twitter, Facebook, etc? }\end{array}$} & \multirow{3}{*}{$\begin{array}{c}\text { ¿Con qué frecuen- } \\
\text { cia te conectas a } \\
\text { Internet? } \\
\text { Media }\end{array}$} \\
\hline & \multicolumn{2}{|c|}{ Televisión } & \multicolumn{2}{|c|}{ Radio } & \multicolumn{2}{|c|}{ Periódico } & \multicolumn{2}{|c|}{ Internet } & \multicolumn{2}{|c|}{ Facebook } & \multicolumn{2}{|c|}{ Twitter } & \multicolumn{2}{|c|}{ Sí } & \multicolumn{2}{|c|}{ No } & \\
\hline & $\mathrm{N}$ & $\%$ & $\mathrm{~N}$ & $\%$ & $\mathrm{~N}$ & $\%$ & $\mathrm{~N}$ & $\%$ & $\mathrm{~N}$ & $\%$ & $\mathrm{~N}$ & $\%$ & $\mathrm{~N}$ & $\%$ & $\mathrm{~N}$ & $\%$ & \\
\hline Siempre & 12 & $5.4 \%$ & 2 & $7.1 \%$ & 0 & $0.0 \%$ & 14 & $10.3 \%$ & 5 & $12.2 \%$ & 0 & $0.0 \%$ & 32 & $7.2 \%$ & 5 & $6.1 \%$ & 1.5 \\
\hline $\begin{array}{l}\text { Cuando se tiene in- } \\
\text { formación y respon- } \\
\text { sabilidad }\end{array}$ & 55 & $24.9 \%$ & 7 & $25.0 \%$ & 18 & $34.0 \%$ & 50 & $36.8 \%$ & 15 & $36.6 \%$ & 0 & $0.0 \%$ & 144 & $32.2 \%$ & 13 & $15.9 \%$ & 1.5 \\
\hline $\begin{array}{l}\text { Cuando hay que } \\
\text { protestar por alguna } \\
\text { injusticia }\end{array}$ & 28 & $12.7 \%$ & 4 & $14.3 \%$ & 5 & $9.4 \%$ & 19 & $14.0 \%$ & 4 & $9.8 \%$ & 2 & $66.7 \%$ & 56 & $12.5 \%$ & 13 & $15.9 \%$ & 1.7 \\
\hline $\begin{array}{l}\text { Cuando se obtiene } \\
\text { algún beneficio }\end{array}$ & 37 & $16.7 \%$ & 2 & $7.1 \%$ & 5 & $9.4 \%$ & 18 & $13.2 \%$ & 3 & $7.3 \%$ & 0 & $0.0 \%$ & 55 & $12.3 \%$ & 16 & $19.5 \%$ & 1.8 \\
\hline Cuando es obligación & 80 & $36.2 \%$ & 11 & $39.3 \%$ & 23 & $43.4 \%$ & 32 & $23.5 \%$ & 12 & $29.3 \%$ & 1 & $33.3 \%$ & $14 \mathrm{l}$ & $31.5 \%$ & 32 & $39.0 \%$ & 1.8 \\
\hline Nunca & 9 & $4.1 \%$ & 2 & $7.1 \%$ & 2 & $3.8 \%$ & 3 & $2.2 \%$ & 2 & $4.9 \%$ & 0 & $0.0 \%$ & 19 & $4.3 \%$ & 3 & $3.7 \%$ & 1.7 \\
\hline
\end{tabular}

Fuente: elaboración propia con base en la Encuesta Nacional de Juventud en Valores 2012, Instituto Mexicano de la Juventud.

Comparamos también las motivaciones precedentes en relación con la habilitación de una cuenta en redes sociales. Aquí los tipos de motivación nula e intrínseca son cercanos ( 4 \% y 7 \% de las personas que tiene una cuenta en RSV suscriben estas posiciones) y es similar en las posiciones intermedias de "cuando se tiene información..." (32 \%) y "cuando es obligación" (32\%); las posiciones también intermedias de protesta por injusticia (13\%) y "cuando se obtiene un beneficio" (12 \%) son prácticamente iguales. En suma, los porcentajes no demuestran una tendencia ascendente de motivación intrínseca o desinteresada en relación con la posesión de una cuenta en redes sociales. Por el contrario, demuestran que las motivaciones condicionadas, por coerción o nulas son significativamente equiparables a las otras en dichos usuarios.

Por otro lado, quisimos poner a prueba el supuesto de que una mayor intensidad en el uso de Internet se relaciona con estos niveles de compromiso. Una observación panorámica permite concluir que en efecto un mayor uso de Internet se relaciona con una predisposición positiva a participar: los usuarios más intensivos ( $\mu=1.5$ en una escala de 4) se asocian a la respuesta de "siempre se debe participar en la política", y el uso va disminuyendo conforme el compromiso se vuelve más tenue, de modo que la posición "cuando se obtiene algún beneficio" (1.8), cuando es obligación (1.8) o nunca (1.7) son superiores; la particularidad es que la diferencia entre los mismos, como se puede observar, es muy modesta y casi insignificante.

Evaluamos, por otro lado, las actividades de participación en relación también con las fuentes de aprendizaje y actividades de tiempo libre, entre las que se incluye Internet y RSV (tabla 3). Respecto a participación pasada, el uso de Internet marca una diferencia 
significativa: de las cuatro variables medidas de participación previa, en todas ellas la participación incrementa cuando los sujetos saben usar Internet o están adscritos a una red social; en otras palabras, quienes no saben usar Internet parecen ser menos participativos que los que sí; de los que "han participado en una organización, asociación, equipo o grupo", el 81 \% tiene Internet y el 18 \% no. La diferencia es menor en cuanto al uso de redes sociales, puesto que el 61 \% de los que han participado están adscritos a ellas, y el 38 \% no. La participación en organizaciones de tipo político se comporta de manera similar, puesto que de los que han participado, el $86 \%$ tiene Internet y el 72 \%, redes sociales, y en esa dirección se orienta la "asistencia a manifestaciones" (78 \% y 64 \%, respectivamente), la "participación actual en organizaciones" (83 \% y 65 \%) y específicamente en aquellas "de tipo político" (85 \% y 70 \%).

Esta orientación se enfatiza cuando la variable de participación se cruza con las actividades en donde pasan su tiempo libre los jóvenes. De quienes alguna vez han participado, el 45 \% lee principalmente en su tiempo libre y 42 \% usa Internet, en contraste con el $18 \%$ que ve TV o el 8 \% que se reúne con amigos. De manera similar, de quienes han asistido a manifestaciones el $14 \%$ lee de manera primordial durante su tiempo libre, el $13 \%$ se conecta a Internet, el $6 \%$ ve TV y el $1 \%$ se reúne con amigos.

Tabla 3. Participación, uso y aprendizaje político a través de Internet

\begin{tabular}{|c|c|c|c|c|c|c|c|c|c|c|c|c|c|}
\hline & & \multicolumn{2}{|c|}{$\begin{array}{l}\text { 1. ¿Alguna vez has } \\
\text { participado en una } \\
\text { organización, asocia- } \\
\text { ción, equipo o grupo? }\end{array}$} & \multicolumn{2}{|c|}{$\begin{array}{l}\text { 2. ¿De tipo } \\
\text { político? }\end{array}$} & \multicolumn{2}{|c|}{$\begin{array}{l}\text { 2. Has asistido a } \\
\text { manifestaciones }\end{array}$} & \multicolumn{2}{|c|}{$\begin{array}{l}\text { 3. Has protestado } \\
\text { por Internet }\end{array}$} & \multicolumn{2}{|c|}{$\begin{array}{l}\text { 4. Actualmente, } \\
\text { ¿participas en alguna } \\
\text { organización, asocia- } \\
\text { ción o grupo? }\end{array}$} & \multicolumn{2}{|c|}{$\begin{array}{l}\text { 5. ¿En uno de tipo } \\
\text { político? }\end{array}$} \\
\hline & & Sí & No & Sí & No & Sí & No & Sí & No & Sí & No & Sí & No \\
\hline \multicolumn{14}{|l|}{ Uso de Internet } \\
\hline \multirow[t]{2}{*}{ ¿Sabes usar Internet? } & Sí & $81.5 \%$ & $58.5 \%$ & $86.7 \%$ & $80.9 \%$ & $78.1 \%$ & $63.8 \%$ & $94.4 \%$ & $63.8 \%$ & $83.6 \%$ & $80.5 \%$ & $85.2 \%$ & $83.5 \%$ \\
\hline & No & $18.5 \%$ & $41.5 \%$ & $13.3 \%$ & $19.1 \%$ & $21.9 \%$ & $36.2 \%$ & $5.6 \%$ & $36.2 \%$ & $16.4 \%$ & $19.5 \%$ & $14.8 \%$ & $16.5 \%$ \\
\hline \multirow{2}{*}{$\begin{array}{l}\text { ¿Tienes 4. Red social } \\
\text { (Face book, Twitter, Hi5)? }\end{array}$} & Sí & $61.7 \%$ & $46.4 \%$ & $72.8 \%$ & $60.0 \%$ & $64.1 \%$ & $50.3 \%$ & $78.4 \%$ & $50.0 \%$ & $65.0 \%$ & $60.0 \%$ & $70.6 \%$ & $64.4 \%$ \\
\hline & No & $38.3 \%$ & $53.6 \%$ & $27.2 \%$ & $40.0 \%$ & $35.9 \%$ & $49.7 \%$ & $21.6 \%$ & $50.0 \%$ & $35.0 \%$ & $40.0 \%$ & $29.4 \%$ & $35.6 \%$ \\
\hline \multicolumn{14}{|c|}{ En tu tiempo libre, ¿cuál es la principal actividad que realizas para divertirte? } \\
\hline Reunirme con amigos & & $8.7 \%$ & $25.5 \%$ & $2.8 \%$ & $31.4 \%$ & $1.5 \%$ & $32.7 \%$ & $4.5 \%$ & $30.5 \%$ & $10.2 \%$ & $24.8 \%$ & $3.6 \%$ & $30.6 \%$ \\
\hline Salir con mi pareja & & $7.0 \%$ & $23.6 \%$ & $2.6 \%$ & $28.0 \%$ & $1.0 \%$ & $29.6 \%$ & $4.5 \%$ & $23.6 \%$ & $8.8 \%$ & $19.4 \%$ & $4.4 \%$ & $25.3 \%$ \\
\hline Conectarme a Internet & & $42.8 \%$ & $57.2 \%$ & $15.2 \%$ & $84.4 \%$ & $13.1 \%$ & $86.4 \%$ & $9.8 \%$ & $89.5 \%$ & $26.8 \%$ & $73.2 \%$ & $15.9 \%$ & $84.1 \%$ \\
\hline Ver televisión & & $18.4 \%$ & $81.6 \%$ & $13.4 \%$ & $84.7 \%$ & $6.5 \%$ & $92.9 \%$ & $1.6 \%$ & $97.8 \%$ & $26.5 \%$ & $73.5 \%$ & $15.4 \%$ & $82.1 \%$ \\
\hline Leer & & $45.8 \%$ & $54.2 \%$ & $13.6 \%$ & $83.6 \%$ & $14.0 \%$ & $85.8 \%$ & $8.0 \%$ & $91.6 \%$ & $36.6 \%$ & $63.4 \%$ & $14.1 \%$ & $85.9 \%$ \\
\hline \multicolumn{14}{|c|}{ ¿De dónde has aprendido lo más importante que sabes sobre política? } \\
\hline La escuela & & $37.2 \%$ & $37.4 \%$ & $36.1 \%$ & $37.6 \%$ & $36.7 \%$ & $37.5 \%$ & $33.3 \%$ & $37.8 \%$ & $35.4 \%$ & $38.1 \%$ & $26.0 \%$ & $36.6 \%$ \\
\hline $\begin{array}{l}\text { Mi casa o en la de algún } \\
\text { pariente }\end{array}$ & & $22.6 \%$ & $19.2 \%$ & $20.1 \%$ & $20.1 \%$ & $21.4 \%$ & $20.1 \%$ & $25.4 \%$ & $22.3 \%$ & $23.5 \%$ & $22.2 \%$ & $31.1 \%$ & $22.5 \%$ \\
\hline Fuera de casa & & $11.8 \%$ & $14.1 \%$ & $14.3 \%$ & $13.4 \%$ & $9.6 \%$ & $13.7 \%$ & $12.1 \%$ & $11.8 \%$ & $12.3 \%$ & $11.6 \%$ & $15.8 \%$ & $11.9 \%$ \\
\hline Medios de comunicación & & $21.5 \%$ & $23.0 \%$ & $22.0 \%$ & $22.7 \%$ & $17.9 \%$ & $22.8 \%$ & $20.6 \%$ & $21.7 \%$ & $21.7 \%$ & $21.5 \%$ & $18.4 \%$ & $22.3 \%$ \\
\hline
\end{tabular}




\begin{tabular}{|c|c|c|c|c|c|c|c|c|c|c|c|c|}
\hline \multirow[b]{2}{*}{ Internet } & \multicolumn{2}{|c|}{$\begin{array}{l}\text { 1. ¿Alguna vez has } \\
\text { participado en una } \\
\text { organización, asocia- } \\
\text { ción, equipo o grupo? }\end{array}$} & \multicolumn{2}{|c|}{$\begin{array}{l}\text { 2. ¿De tipo } \\
\text { político? }\end{array}$} & \multicolumn{2}{|c|}{$\begin{array}{l}\text { 2. Has asistido a } \\
\text { manifestaciones }\end{array}$} & \multicolumn{2}{|c|}{$\begin{array}{l}\text { 3. Has protestado } \\
\text { por Internet }\end{array}$} & \multicolumn{2}{|c|}{$\begin{array}{l}\text { 4. Actualmente, } \\
\text { ¿participas en alguna } \\
\text { organización, asocia- } \\
\text { ción o grupo? }\end{array}$} & \multicolumn{2}{|c|}{$\begin{array}{l}\text { ¿En uno de tipo } \\
\text { político? }\end{array}$} \\
\hline & $2.3 \%$ & $1.4 \%$ & $1.9 \%$ & $1.6 \%$ & $6.2 \%$ & $1.4 \%$ & $3.4 \%$ & $2.2 \%$ & $2.3 \%$ & $2.3 \%$ & $3.6 \%$ & $2.1 \%$ \\
\hline Libros & $2.9 \%$ & $2.7 \%$ & $4.0 \%$ & $2.6 \%$ & $6.0 \%$ & $2.6 \%$ & $4.1 \%$ & $2.6 \%$ & $3.2 \%$ & $2.7 \%$ & $4.6 \%$ & $2.9 \%$ \\
\hline
\end{tabular}

Fuente: elaboración propia en base a la Encuesta Nacional de la Juventud 2010, Instituto Mexicano de la Juventud.

Las diferencias se reducen respecto a la participación actual, en donde hay menor contraste. De los que actualmente participan, el $26 \%$ se conecta a Internet de manera preferente, el $26 \%$ ve TV y el $36 \%$ lee libros. Este menor contraste también se aplica a la participación actual en organizaciones de tipo político (de los que participan, el $15 \%$ se conecta a Internet, $15 \%$ ve TV y 14 \% lee libros), aunque también a la pasada (15\%, $13 \%$ y $13 \%$, respectivamente).

No obstante estas cifras, las personas participativas no necesariamente reconocen que Internet ha sido un medio del que pueden obtener mucho aprendizaje. Al comparar las distintas agencias que se reconocen como lugares de aprendizaje, observamos que de los que han participado, el $37 \%$ reconoce que de la escuela han aprendido más sobre política; 22 \%, de su casa, y el 21 \% de los medios. Solo el 2 \% de los que han participado reconoce haber aprendido lo más importante de política en Internet. Todas las variables se comportan de manera similar y no exceden el $3 \%$ de las personas que participan de alguna manera y que afirman haber aprendido de Internet; en todas, por cierto, la escuela, el hogar y los medios, en ese orden, son las agencias más relevantes. Solo se encuentra una ligera variación en la asistencia a manifestaciones, en donde los medios de comunicación como agente principal de conocimiento retroceden un tanto (17 \%) respecto a Internet (6\%).

Asimismo, obtuvimos resultados respecto a la predisposición a la participación política en determinadas actividades, la cual se revela como relacionada en buena medida con el uso preferencial de los medios (tabla 4). En esta tabla comparamos los porcentajes de usuarios de cada medio que están dispuestos a participar, con los que no. Por lo regular los que usan Internet presentaron una predisposición más favorable a la participación que los que usan otros medios, en el contexto de una baja predisposición en general.

El porcentaje de personas que usa Internet y está dispuesta a asistir a marchas o manifestaciones es del $19 \%$, ligeramente superior al $10 \%$ de quienes prefieren TV y al 13 $\%$ de quienes prefieren radio; el porcentaje de usuarios de Facebook, por cierto, es reducido, e incluso, menor al de usuarios de TV. Asimismo, el porcentaje de personas que usan Internet y están dispuestas a quejarse ante las autoridades también es notorio, ya que el 15 \% se manifestó en ese sentido, así como el 14 \% de los que usan Facebook superando ambos casos ligeramente a los usuarios de TV (11 \%) y periódicos (9\%). A partir de ahí otras actividades que involucran participación muestran porcentajes más bajos en relación con el consumo de medios, aunque siempre iguales o superiores que otros medios de comunicación. Los porcentajes son mínimos en "Apoyar activamente en campañas" (8\%), "participar en un blog o foro" (10 \%) o "acudir a reuniones políticas convocadas en redes 
sociales" (4 \%), y similares para usuarios de Facebook (7 \%, 10 \% y 2 \%, respectivamente). No obstante, son superiores a otros medios, en ciertos casos de manera discreta ("acudir a reuniones políticas..." tiene el $3 \%$ en radio y $4 \%$ en TV, comparado con $4 \%$ de Internet) o significativas ("participar en un blog..." tiene el $10 \%$ para Internet y $10 \%$ para Facebook, mientas que los usuarios de TV y prensa tienen $4 \%$ ).

Tabla 4. Predisposición a participar en ciertas actividades, en relación al consumo de medios

\begin{tabular}{|c|c|c|c|c|c|c|c|c|c|c|c|c|c|c|c|c|c|c|c|c|}
\hline & \multicolumn{4}{|c|}{$\begin{array}{l}\text { Asistir a manifestaciones, } \\
\text { marchas o movilizaciones. }\end{array}$} & \multicolumn{4}{|c|}{$\begin{array}{l}\text { Quejarse ante las } \\
\text { autoridades }\end{array}$} & \multicolumn{4}{|c|}{$\begin{array}{l}\text { Apoyar activamente } \\
\text { campañas electorales }\end{array}$} & \multicolumn{4}{|c|}{$\begin{array}{c}\text { Participar } \\
\text { en un blog o foro }\end{array}$} & \multicolumn{4}{|c|}{$\begin{array}{c}\text { Acudir a reuniones políticas } \\
\text { convocadas en redes } \\
\text { sociales }\end{array}$} \\
\hline & \multicolumn{2}{|r|}{ Sí } & \multicolumn{2}{|c|}{ No } & \multicolumn{2}{|r|}{ Sí } & \multicolumn{2}{|c|}{ No } & \multicolumn{2}{|c|}{ Sí } & \multicolumn{2}{|r|}{ No } & \multicolumn{2}{|r|}{ Sí } & \multicolumn{2}{|r|}{ No } & \multicolumn{2}{|r|}{ Sí } & \multicolumn{2}{|r|}{ No } \\
\hline & $\mathrm{N}$ & $\%$ & $\mathrm{~N}$ & $\%$ & $\mathrm{~N}$ & $\%$ & $\mathrm{~N}$ & $\%$ & $\mathrm{~N}$ & $\%$ & $\mathrm{~N}$ & $\%$ & $\mathrm{~N}$ & $\%$ & $\mathrm{~N}$ & $\%$ & $\mathrm{~N}$ & $\%$ & $\mathrm{~N}$ & $\%$ \\
\hline \multicolumn{21}{|c|}{67 ¿Cuál es el medio de comunicación que más utilizas para informarte de lo que pasa en el país? } \\
\hline Televisión & 25 & $10.4 \%$ & 215 & $89.6 \%$ & 26 & $10.8 \%$ & 214 & $89.2 \%$ & 13 & $5.4 \%$ & 227 & $94.6 \%$ & 9 & $3.8 \%$ & 230 & $96.2 \%$ & 8 & $3.3 \%$ & 232 & $96.7 \%$ \\
\hline Radio & 4 & $13.8 \%$ & 25 & $86.2 \%$ & 6 & $20.7 \%$ & 23 & $79.3 \%$ & 2 & $6.9 \%$ & 27 & $93.1 \%$ & 1 & $\%$ & 28 & $96.6 \%$ & 1 & $3.6 \%$ & 27 & $96.4 \%$ \\
\hline Periódico & 6 & $10.7 \%$ & 50 & $89.3 \%$ & 5 & $8.9 \%$ & 51 & $91.1 \%$ & 5 & $9.1 \%$ & 50 & $90.9 \%$ & 2 & $3.6 \%$ & 54 & $96.4 \%$ & 0 & $0.0 \%$ & 56 & $100.0 \%$ \\
\hline Internet & 28 & $19.4 \%$ & 116 & $80.6 \%$ & 22 & $15.3 \%$ & 122 & $84.7 \%$ & 12 & $8.4 \%$ & 131 & $91.6 \%$ & 14 & $9.9 \%$ & 127 & $90.1 \%$ & 6 & $4.3 \%$ & 135 & $95.7 \%$ \\
\hline Facebook & 4 & $9.5 \%$ & 38 & $90.5 \%$ & 6 & $14.3 \%$ & 36 & $85.7 \%$ & 3 & $7.1 \%$ & 39 & $92.9 \%$ & 4 & $9.5 \%$ & 38 & $90.5 \%$ & 1 & $2.4 \%$ & 41 & $97.6 \%$ \\
\hline Twitter & 1 & $25.0 \%$ & 3 & $75.0 \%$ & 0 & $0.0 \%$ & 4 & $100.0 \%$ & 1 & $25.0 \%$ & 3 & $75.0 \%$ & 0 & $0.0 \%$ & 4 & $100.0 \%$ & 0 & $0.0 \%$ & 4 & $100.0 \%$ \\
\hline & $\mu$ & $\begin{array}{l}\text { Desv. } \\
\text { est. }\end{array}$ & $\mu$ & $\begin{array}{l}\text { Desv. } \\
\text { est. }\end{array}$ & $\mu$ & $\begin{array}{l}\text { Desv. } \\
\text { est. }\end{array}$ & $\mu$ & $\begin{array}{l}\text { Desv. } \\
\text { est. }\end{array}$ & $\mu$ & $\begin{array}{l}\text { Desv. } \\
\text { est. }\end{array}$ & $\mu$ & $\begin{array}{l}\text { Desv. } \\
\text { est. }\end{array}$ & $\mu$ & $\begin{array}{l}\text { Desv. } \\
\text { est. }\end{array}$ & $\mu$ & $\begin{array}{l}\text { Desv. } \\
\text { est. }\end{array}$ & $\mu$ & $\begin{array}{l}\text { Desv. } \\
\text { est. }\end{array}$ & $\mu$ & Desv.est. \\
\hline \multicolumn{21}{|c|}{65 ¿Con qué frecuencia te conectas a Internet? } \\
\hline & 1.4 & 0.7 & 1.7 & 1 & 1.5 & 0.8 & 1.7 & 0.9 & 1.6 & 1.0 & 1.6 & 0.9 & 1.3 & 0.6 & 1.7 & 0.9 & 1.4 & 0.8 & 1.7 & 0.9 \\
\hline
\end{tabular}

Fuente: elaboración propia con base en la Encuesta Nacional de Juventud en Valores 2012, Instituto Mexicano de la Juventud.

Las predisposiciones de usuarios de Twitter también son significativas, particularmente en la asistencia a marchas o en el apoyo a campañas, aunque la reducida frecuencia de usuarios dificulta elaborar descripciones cuantitativas relevantes.

Por otro lado, la sola suscripción a redes sociales pudiera estar vinculada con la realización de estas actividades, para lo cual efectuamos correlaciones de Pearson con medida de V de Cramer. De las cinco actividades exploradas sólo el "apoyo en campañas electorales" está relacionado c2(6, N =570)=142.363, p =.000, y de manera significativa (V de Cramer $=.353$ ); también se relaciona positivamente la frecuencia de conexión a Internet con esta actividad, $\mathrm{c} 2(15, \mathrm{~N}=570)=27.993, \mathrm{p}=.022$, aunque de manera modesta (V de Cramer $=.134$ ). El resto de las actividades no pasaron la prueba de significancia y no manifiestan relación estadística relevante.

Finalmente observamos si hay una diferencia relevante entre las frecuencias de uso de Internet para quienes están dispuestos a realizar la actividad y quienes no, en el supuesto de que quienes utilizan más el medio están más predispuestos a participar. Respecto a las distintas actividades observamos nula diferencia entre quienes apoyan campañas electorales y quienes no, y un consumo ligeramente mayor en quienes están dispuestos 
a participar en el resto de las actividades. Este incremento va de 0.2 para quienes se "quejan ante las autoridades", 0.3 para quienes "asisten a manifestaciones..." o "acuden a reuniones políticas" y 0.4 para quienes "participan en un blog o foro".

\section{Conclusiones}

Los datos descritos presentan un panorama que, en efecto, relaciona positivamente el uso de Internet y las RSV con la participación política en varios indicadores; sin embargo, esa relación es modesta, poco significativa. Esto se confirma a lo largo de las diversas variables analizadas.

En cuanto a los usos de dicha tecnología podemos afirmar que existen condiciones para la formación de comunidades de sentido, subculturas o microsociedades mediante Internet, a partir de los usos de vinculación horizontal que les dan los sujetos; no obstante, es incierto si dicha vinculación se utiliza para fines políticos, puesto que una proporción muy reducida de usuarios consulta contenidos vinculados con lo público o lo político.

Con respecto al interés en participar en actividades políticas este sí varía a favor de usuarios de Internet en comparación con usuarios de otros medios, pero por muy poco. A su vez, no hay diferencia alguna en los niveles de interés de quienes poseen una cuenta en redes sociales y los que no; tampoco esto introduce una variación relevante en la participación actual.

Este mismo patrón se presenta con la variable "motivación a participar", relativamente baja para los usuarios de los distintos medios, y en el caso de usuarios de Internet, poco distanciada respecto a los demás. En ese contexto la motivación intrínseca es superior en usuarios de Internet respecto a usuarios de otros medios, las motivaciones condicionadas son inferiores y la no motivación es inferior en usuarios de Internet respecto a usuarios de los demás medios, pero en todos los casos la diferencia es mínima. Por otro lado, en efecto hay una relación entre la intensidad en el uso de Internet y la motivación, pero esta resulta modesta.

Por otro lado, el uso de Internet y su consideración como fuente privilegiada de aprendizaje se relaciona con una mayor participación en el pasado; quienes tienen acceso tanto al medio como a las redes sociales sienten una distancia significativa en cuanto a participación pasada respecto a quienes no, o a quienes ven televisión de manera preferente. No obstante tal participación parece ser efímera, puesto que la participación actual no es muy diferente entre quienes de manera preferente ven televisión o leen libros, y quienes se conectan a Internet. Tampoco la red parece que ha servido como fuente de aprendizaje para la participación, puesto que los más participativos reportan haber aprendido muy poco por Internet en comparación con los medios, el hogar o la escuela.

Finalmente, la disposición a participar en ciertas actividades políticas solo está significativamente relacionada con la disponibilidad de una cuenta en redes sociales en cuanto al "apoyo en campañas electorales", una actividad con diversos mecanismos on 
line de participación. También se manifiesta una ventaja de los usuarios de Internet respecto a su disposición a asistir a manifestaciones o quejarse ante las autoridades, aspecto también ventajoso para usuarios de redes sociales; no obstante, en otras actividades se presentan relaciones iguales o superiores respecto a usuarios de otros medios de comunicación.

Es así que por lo menos en el caso de los jóvenes, el uso de Internet presenta una relación ligeramente superior, poco significativa, con la participación política, de manera que se verifica la tesis de la normalización según la cual la irrupción de dichas tecnologías es provechosa solo para los más politizados, y modesta para el resto.

De esta manera se rechaza la hipótesis de que las formas de socialización vertical y horizontal que Internet ha facultado en las generaciones recientes, en conjunción con las condiciones de democratización, colonización de Internet y tiempo libre, han tenido un efecto significativo en los niveles de participación de los usuarios jóvenes y asiduos de Internet. En ese sentido es posible especular que el estado de la cultura política en México es tan precario que las nuevas tecnologías y circunstancias sociopolíticas no alcanzan a introducir variaciones significativas en los comportamientos políticamente relevantes; en términos de socialización política los datos significan que Internet complementa moderadamente, mas no supera de manera importante, los otros recursos mediáticos de integración juvenil al orden político.

No obstante, alrededor de la teorización construida pudieran desarrollarse formas de medición empírica con una operacionalización exprofeso, en lugar del uso de datos secundarios, capaces de captar de mejor manera las relaciones aquí esgrimidas. Desde luego también se necesitan diseños cualitativos más sensibles a las prácticas y dinámicas de conformación en Internet de subculturas juveniles que giran alrededor de objetos políticos. A estas tareas y otras más pudieran abocarse los esfuerzos de investigación futura.

\section{Referencias bibliográficas}

Aguilera, O. (2003). Un modelo transoceánico para armar. Algunas hipótesis acerca del vínculo entre juventud y política. JóVENES. Revista de Estudios sobre Juventud, 7(19), 64-81.

Anduiza, E., Gallego, A., E Cantijoch, M. (2010). Online Political Participation in Spain: The Impact of Traditional and Internet Resources. Journal of Information Technology and Politics, 7(4), 356-368.

Bakker, T. P., \& de Vreese, C. H. (2011). Good News for the Future? Young People, Internet Use, and Political Participation. Communication Research, XX(10), 1-20.

Balardini, S. (2005). ¿Qué hay de nuevo viejo?: una mirada sobre los cambios en la participación política juvenil. Nueva Sociedad(200), 96-107.

Baumgartner, J. C., \& Morris, J. S. (2010). MyFaceTube Politics. Social Networking Web Sites and Political Engagement of Young Adults. Social Science Computer Review, 28(1), 24-44.

Benedicto, J. (2008). Jóvenes y participación política: investigaciones europeas. Revista de Estudios de Juventud.(81), 13-28. 
Brito, R. (1998). Hacia una sociología de la juventud. Algunos elementos para la deconstrucción de un nuevo paradigma de la juventud. Última década(9), 1-7.

Calderón, L. (2004). Socialización política. En L. Baca, J. Bosker-Liwerant, F. Castañeda, I. Cisneros \& G. Pérez (Eds.), Léxico de la Política (pp. 695-697). México: Fondo de Cultura Económica.

Cárdenas, M., Parra, L., Picón, J., Pinead, H., \& Rojas, R. (2007). Las representaciones sociales de la política y la democracia. Ultima Década, 26, 53-78.

Corduneanu, I. (2012). Jóvenes, "¿un lujo de clase?". Juventud y actitudes políticas hacia el 2012. Revista Mexicana de Opinión Pública, 77-95.

Díaz Nosty, B. (2007). Tendencias 07. Medios de Comunicación. El escenario iberoamericano. Madrid: Ariel, Fundación Telefónica.

Dudley, R. L., E Gitelson, A. R. (2002). Political literacy, civic education, and civic engagement: A return to political socialization? Applied Developmental Science, 6(4), 175-182.

Echeverría, M. (2010). Cibercampañas e inclusión ciudadana. Del potencial cívico de los sitios de campaña en las elecciones legislativas de 2009. Sociológica, 25(72), 71-108.

Estrada, M. (2008). Campo político y juventud: análisis en dos dispositivos de Morelos. de la negación del otro a la política como servicio. Espiral. Estudios sobre Estado y Sociedad, XIV(42), 145 178.

Feixa, C. (1999). De jóvenes, bandas y tribus. Antropología de la juventud. Barcelona: Ariel.

Fernández, A. (2003). Cultura política y jóvenes en el umbral del tercer milenio. México: Instituto Mexicano de la Juventud.

Fernández Poncela, A. (2009). Desafección política juvenil: Desconfianza, desinterés y abstencionismo. Casa del Tiempo, II(18), 83-89.

Gil de Zúniga, H., Nakwon, J., \& Valenzuela, S. (2012). Social Media Use for News and Individuals' Social Capital, Civic Engagement and Political Participation. Journal of Computer-Mediated Communication, 17, 319-339.

Guerrero, M. A., Rodríguez-Oreggia, E., \& Machuca, C. (2014). Consumo informativo y culturas cívicas: el papel de internet y las audiencias proactivas. En G. Meixueiro $\&$ A. Moreno (Eds.), El comportamiento electoral mexicano en las elecciones de 2012. Análisis del proyecto comparativo de las elecciones nacionales (CNEP). México: Centro de Estudios Sociales y de Opinión Pública, ITAM.

Hermes, J. (2006). Citizenship in the Age of the Internet. European Journal of Communication, 21 (3), 295-309.

Ibarra, A. (2003). Televisión y socialización política de escolares en la zona metropolitana de Guadalajara. Doctorado, Universidad de Guadalajara, Guadalajara.

IFE. (2003). Estudio sobre lo cívico y lo político en las narrativas culturales de los jóvenes mexicanos. México: IFE.

IMJUVE. (2011). Encuesta Nacional de la Juventud 2010. Resultados generales. 1 44. Recuperado de http://www.sep.gob.mx/work/models/sep 1/Resource/2249/1/images/EncuestaNacional\%20deJuventud\%20 2010\%20-\%20Resultados\%20Generales_18nov11.pdf

Lastra, M. G. (2006). Política y mundo universitario: algunos datos sobre la cultura política del alumnado en la Universidad de Cantabria. Perfiles Educativos, XXVIII(114), 152-168. 
Macassi, S. (2001). Culturas juveniles, medios y ciudadanía. El nuevo horizonte generacional y las disyuntivas de la inserción de los jóvenes en la sociedad. Lima: Asociación de Comunicadores Sociales Calandria.

Mazzoleni, G. (2001). La revolución simbólica de Internet. Cuadernos de Información y Comunicación(6), 33-38.

Megías, E. (Ed.). (2005). Jóvenes y política. El compromiso con lo colectivo. Madrid: INJUVE.

Muñiz, C., \& Corduneanu, I. (2014). El papel mediador de la conversación política en la generación de participación política: evidencias desde una perspectiva generacional comparativa. En G. Meixueiro \& A. Moreno (Eds.), El comportamiento electoral mexicano en las elecciones de 2012. Análisis del Proyecto Comparativo de Elecciones Nacionales (CNEP). México: Centro de Estudios Sociales y de Opinión Pública, ITAM.

Portillo, M. (2003). Juventud y Política, representaciones en el discurso de los jóvenes de la Ciudad de México. Jovenes, Revista de Estudios sobre Juventud(19), 220-245.

Portillo, M. (2004). Culturas juveniles y cultura política: la construcción de la opinión política de los jóvenes de la ciudad de México. Doctorado, Universidad Autónoma de Barcelona, Barcelona.

Sánchez, E. (1996). Cultura política y medios de difusión: educación informal y socialización. En E. Krotz (Ed.), El estudio de la cultura política en México: Perspectivas disciplinarias y actores políticos. México: Conaculta/CIESAS.

Sandoval, J., E Hatibovic, F. (2010). Socialización política y juventud: el caso de las trayectorias ciudadanas de los estudiantes universitarios de la región de Valparaíso. Última Década(32), 11-36.

Tedesco, J. (2004). Changing the Channel: Use of the Internet for Communicating About Politics. En L. L. Kaid (Ed.), Hanbook of Political Communication Research. New Jersey: Laurence Elrbaum Associates.

Valenzuela, S., Park, N., \& Kee, K. F. (2009). Is There Social Capital in a Social NetworkSite?: Facebook Use and College Students'Life Satisfaction, Trust, and Participation. Journal of Computer-Mediated Communication, 14, 875-901.

Vitak, J., Zube, P., Smock, A., Carr, C. T., Ellison, N., E Lampe, C. (2010). It's Complicated: Facebook Users' Political Participationin the 2008 Election. CyberPsychology, Behavior and Social Networking, $0(0), 1-8$.

Ward, J. (2005). An opportunity for engagement in cyberspace: Political youth Web sites during the 2004 European Parliament election campaign. Information Polity(10), 233-246.

Zabludovsky, G. (2012). Individualización y juventud en México: educación, actitudes laicas y redes mediáticas Retrieved 5/8, 2013, from http://estepais.com/site/?p=36705

Zarzuri, R. (2010). Tensiones y desafíos en la participación política juvenil en Chile. Utopía y Praxis Latinoamericana, 15(50), 103-115. 
